\title{
Dynamic Increase of Red Cell Distribution Width Predicts Increased Risk of 30-Day Readmission in Patients with Acute Exacerbation of Chronic Obstructive Pulmonary Disease
}

International Journal of Chronic Obstructive Pulmonary Disease

\section{Mengpei Zhu (D) \\ Lisong Dai $\mathbb{D}^{2}$ \\ Lei $\mathrm{Wan}^{3}$ \\ Shuling Zhang' \\ Hongxing Peng'}

'Department of Respiratory Medicine, Liyuan Hospital, Tongji Medical College of Huazhong University of Science and Technology, Wuhan, Hubei, People's Republic of China; ${ }^{2}$ Radiology Department, Liyuan Hospital, Tongji Medical College of Huazhong University of Science and Technology, Wuhan, Hubei, People's Republic of China; ${ }^{3}$ Department of Cardiovascular Medicine, Liyuan Hospital, Tongji Medical College of Huazhong University of Science and Technology, Wuhan, Hubei, People's Republic of China
Correspondence: Hongxing Peng Department of Respiratory Medicine, Liyuan Hospital, Tongji Medical College of Huazhong University of Science and Technology, Wuhan, Hubei, People's Republic of China

Email penghx2008@I26.com
Purpose: Studies have demonstrated that red blood cell distribution width (RDW) is closely associated with the prognosis of patients with chronic obstructive pulmonary disease (COPD). In addition, the dynamic changes in RDW appear to play an important role. Thus, we aimed to investigate the relationship between dynamic changes in RDW and 30day all-cause readmission of patients with acute exacerbation of COPD (AECOPD).

Methods: In this retrospective cohort study, we enrolled patients with AECOPD hospitalized in the Department of Respiratory Medicine in Liyuan Hospital (Wuhan China), a tertiary, university-affiliated, public hospital. Patients with AECOPD were divided into three groups based on their RDW values after the first and fourth days of admission. The normal range for RDW is $10-15 \%$. Patients with normal RDW values were included in the normal group. Patients with an RDW value $>15 \%$ on the first day, which subsequently decreased by $>2 \%$ on the fourth day was included in the decreased group. The increased group was comprised of patients with an RDW value $>15 \%$ on the first day which continued to increase, or those with a normal RDW value on the first day which increased $>15 \%$ on the fourth day.

Results: A total of 239 patients (age: 72 years [range: 64-81 years]; male: $n=199$ [83.3\%]) were included. There were 108, 72, and 59 patients in the RDW normal, decreased, and increased groups, respectively; the 30-day all-cause readmission rate was $9.3 \%, 9.7 \%$, $27.1 \%$, respectively; $(\mathrm{p}=0.003)$, being noticeably higher in the RDW increased group. Dynamic increase of RDW (OR:3.45, 95\% CI: 1.39-8.58, p=0.008) was independently correlated with 30-day all-cause readmission of patients with AECOPD.

Conclusion: The dynamic increase of RDW is an independent prognostic factor of 30-day all-cause readmission of patients with AECOPD.

Keywords: RDW, chronic obstructive pulmonary disease, hospitalization, readmission, prognosis

\section{Introduction}

As the third-leading cause of death worldwide, chronic obstructive pulmonary disease (COPD) affects 174 million individuals worldwide. ${ }^{1,2}$ COPD is characterized by expiratory airflow limitation that is not fully reversible, deregulated chronic inflammation, and emphysematous destruction of the lungs. ${ }^{3}$ Among patients hospitalized for exacerbation of COPD in different developed countries, including the United States of America, Canada, and Spain, the 30-day 
readmission rate is between $14 \%$ and $22 \% .^{4-7}$ Early readmissions are linked to increased morbidity, worsened disease severity, and increased mortality, and they contribute significantly to the economic burden associated with COPD. ${ }^{4}$ Owing to these data, early identification and intervention readmission have become a priority area for clinicians. In 2014, COPD was included as a condition under the Medicare Hospital Readmissions Reduction Program in the United States of America. However, there is limited evidence to guide hospitals regarding the identification of patients at a higher risk of readmission. ${ }^{4}$

Red blood cell distribution width (RDW) is a simple parameter of the blood count, which reflects the degree of heterogeneity of the erythrocyte volume. ${ }^{8}$ Studies have shown that RDW, particularly dynamic changes in RDW tracked by continuous measurement, has strong prognostic value for various diseases, ${ }^{9-15}$ including cardiovascular and cerebrovascular diseases, cancer, lung diseases, diabetes, sepsis, and liver and kidney failure. According to previous studies, RDW is a marker of inflammation, disease severity, comorbidities, and poor prognosis in patients with COPD. All these factors are associated with early readmission after an acute exacerbation of COPD (AECOPD). ${ }^{4,16}$ Thus, the changes in RDW may be used by physicians for the stratification of readmission risk. In this study, we investigated the relationship between dynamic changes in RDW and 30-day all-cause readmission of patients with AECOPD.

\section{Materials and Methods}

\section{Study Design}

We conducted a retrospective study on acute exacerbations in patients with COPD hospitalized in the Department of Respiratory Medicine of the Liyuan Hospital affiliated to Tongji Medical College, Huazhong University of Science and Technology (Wuhan, China), a tertiary, university-affiliated, public hospital, between January 1, 2018 and June 1, 2020. The study was conducted in accordance with the tenets of the Declaration of Helsinki. The research protocol was approved by the Medical Ethics Committee of Liyuan Hospital, Tongji Medical College, Huazhong University of Science and Technology (IRB ID: [2020] IEC (A012)). All data used in the study were anonymized and the requirement for informed consent was waived.

\section{Participants}

We collected patients with COPD admitted to the hospital due to acute exacerbations. The inclusion criteria were as follows: adult patients diagnosed with COPD by a physician in accordance with the 2020 Global Initiative for Chronic Obstructive Lung Disease guidelines, which is a post-bronchodilator forced expiratory volume in $1 \mathrm{~s} /$ forced vital capacity $(\mathrm{FEV} 1 / \mathrm{FVC})$ ratio $<0.7$. Acute exacerbation was defined as shortness of breath, expectoration of sputum, color change of sputum, cough, wheezing, chest tightness, etc., with aggravation or reappearance of at least two symptoms. Patients diagnosed with uncured malignancy, acute pulmonary embolism, immune diseases, renal failure, only a single RDW, and hospitalization stay $<3$ days were excluded from the study.

\section{Data Collection}

Data on demographic characteristics and comorbidities, such as age, sex, smoking history, admission to a respiratory intensive care unit, complications (hypertension, diabetes mellitus, chronic heart failure, coronary atherosclerotic heart disease, and malignancy), laboratory results, and length of hospital stay were manually reviewed and collected from the medical records by two reviewers. RDW was measured using an automated hematology analyzer (Sysmex XN-9000; Sysmex, Kobe, Japan). In our laboratory, the normal reference range for RDW is $10-15 \%$. Patients were divided into three groups based on their RDW values obtained on the first and fourth day after admission. Patients with normal RDW values were included in the normal group. Patients with an RDW value $>15 \%$ on the first day, which subsequently decreased by $>2 \%$ on the fourth day RDW was included in the decreased group. The increased group was comprised of patients with an RDW value $>15 \%$ on the first day which continued to increase, or those with a normal RDW value on the first day which increased $>15 \%$ on the fourth day.

\section{Statistical Analysis}

Continuous variables were expressed as the mean \pm standard deviation or median (interquartile range). Categorical variables were presented as numbers with percentages. The baseline characteristics of the groups were compared using one-way analysis of variance. The independent sample Kruskal-Wallis $H$-test and chi-squared test were used for continuous and categorical variables, respectively. The 
prognostic value of the changes in RDW on 30-day readmission was determined using logistic regression model, and the results were presented as odds ratios (ORs) and the 95\% confidence intervals (CIs). Variables were selected as candidates for the multivariate analysis when $p<0.1$ in the univariate analysis. Cox regression analysis generated adjusted survival curves between the RDW groups. The p-values $<0.05$ denoted statistically significant differences. All statistical analyses were conducted using SPSS (version 26.0 for Mac OS X; IBM Corporation, Armonk, NY, USA).

\section{Results}

A total of 239 patients with AECOPD (Figure 1) (age: 72 years [range: 64-81 years]; male: $n=199$ [83.3\%]) who met the inclusion criteria were included in our study (Table 1). There were $108(45.2 \%), 72(30.1 \%)$, and 59 (24.7\%) patients in the RDW normal, decreased, and increased groups, respectively. The proportions of patients with previous smoking history and currently smoking were $47.3 \%$ and $19.7 \%$, respectively. The clinical characteristics of each group are shown in Table 1. Compared with the RDW normal group and the RDW decreased group, the RDW increased group had a higher white blood cell count $(\mathrm{p}=0.025)$, neutrophil count $(\mathrm{p}=0.015)$, neutrophil-tolymphocyte ratio $(\mathrm{p}=0.033)$, platelet-lymphocyte ratio $(\mathrm{p}=0.015)$, and $\mathrm{C}$-reactive protein levels $(\mathrm{p}=0.018)$, but lower hemoglobin levels $(\mathrm{p}=0.031)$. Compared with the first two groups, the RDW increased group had higher 30day all-cause readmission rate $(\mathrm{p}=0.003)$.

Thirty-three patients $(13.8 \%)$ returned to the hospital within 30 days after discharge. The 30-day all-cause readmission rate was $9.3 \%(n=10), 9.7 \%(n=7)$, and $27.1 \%$

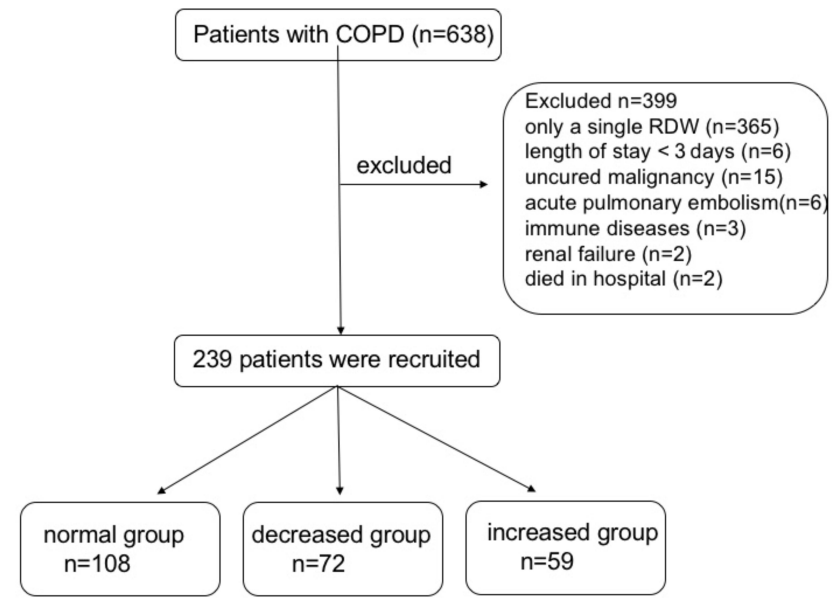

Figure I Flow diagram of enrolled patients. $(n=16)$ in the RDW normal, decreased, and increased groups, respectively $(\mathrm{p}=0.003) . \mathrm{pH}<7.35$ at discharge $(p=0.041)$, coronary heart disease $(p=0.005)$, Charlson comorbidity index $(\mathrm{p}=0.011)$ and increasing $\mathrm{RDW}$ group (OR: 3.45 , 95\% CI: $1.39-8.58, \mathrm{p}=0.008$ ) were the only variables associated with 30-day readmission in AECOPD patients (Table 2). Then, we evaluated the prognostic value of increasing RDW for 30-day readmission, and the negative predictive values of increasing RDW were $90.6 \%$. We used Cox regression model to generate an adjusted survival curve for each RDW group $(\mathrm{p}=0.015)$ (Figure 2).

\section{Discussion}

To our knowledge, this is the first study to investigate the relationship between dynamic changes in RDW and prognosis in patients with AECOPD. In this retrospective investigation, we confirmed that a dynamic increase in RDW is independently associated with an increased risk for 30-day readmission of patients with AECOPD.

Although an elevated RDW is related to prognosis in a variety of diseases, the pathophysiological mechanism involved in this process has not been fully understood. Thus, we attempted to provide a reasonable explanation for the link between an increase in RDW and the 30-day readmission rate.

Firstly, in response to decreased oxygen partial pressure, the renal cortex secretes erythropoietin into the circulation via hypoxia-inducible transcription factors. ${ }^{10}$ Erythropoietin induces the formation of enlarged red blood cells, which can alter the RDW value. ${ }^{10}$ Although chronic and profound hypoxemia are easily diagnosable in clinical practice, the diagnosis of intermittent hypoxemia is challenging. An increase in RDW may also play a role in the early diagnosis of intermittent hypoxia. ${ }^{17} \mathrm{~A}$ high RDW value may be a more reliable marker of tissue hypoxia. ${ }^{18}$ Previous studies demonstrated that hypoxia may contribute to an increase in cardiac load and risk for cardiovascular events. ${ }^{19}$ Therefore, high RDW values may be predictive of poor prognosis due to tissue hypoxia.

Secondly, studies have indicated that high RDW values are associated with inflammation and oxidative stress. Inflammatory cytokines inhibit erythropoietin-induced maturation and proliferation of erythrocytes, which leads to the release of immature erythrocytes into the circulation and an increase in RDW. ${ }^{20}$ Evidence suggests that red blood cells are highly sensitive to oxidative stress, which shortens their life span and increases the RDW. ${ }^{21}$ It has been shown that the RDW increases under stress 
Table I Baseline Characteristics of Three Groups

\begin{tabular}{|c|c|c|c|c|}
\hline Variable & $\begin{array}{l}\text { Normal Group } \\
(n=108)\end{array}$ & $\begin{array}{l}\text { Decreasing Group } \\
(n=72)\end{array}$ & $\begin{array}{l}\text { Increasing Group } \\
(n=59)\end{array}$ & p value \\
\hline Age, years (IQR) & $72(64,8 I)$ & $73(65,80)$ & $73(62,82)$ & 0.893 \\
\hline Male gender, n (\%) & $89(82.4 \%)$ & $61(84.7 \%)$ & $49(83.1 \%)$ & 0.919 \\
\hline Current smoker, n (\%) & $24(22.2 \%)$ & II (I5.3\%) & $12(20.3 \%)$ & 0.513 \\
\hline Charlson comorbidity index, (IQR) & $5(4,6)$ & $5(4,6)$ & $5(4,6)$ & 0.522 \\
\hline Heart rate, beats/min (IQR) & $72.25(82.00,92.75)$ & $72(82,86)$ & $80(72,91)$ & 0.256 \\
\hline Respiratory rate, breath/min (IQR) & $19(20,23)$ & $20(20,23)$ & $19(20,23)$ & 0.734 \\
\hline SO2<90\% at admission, $\mathrm{n}(\%)$ & $44(40.7 \%)$ & $28(38.9 \%)$ & $24(40.7 \%)$ & 0.966 \\
\hline Systolic blood pressure, $\mathrm{mmHg}(\mathrm{SD})$ & $120.19 \pm 15.37$ & $116.32 \pm 13.57$ & $116.54 \pm 15.95$ & 0.155 \\
\hline Hypertension, n (\%) & $39(36.1 \%)$ & $22(30.6 \%)$ & $13(22.0 \%)$ & 0.171 \\
\hline Diabetes, n (\%) & $25(23.1 \%)$ & $9(12.5 \%)$ & $10(16.9 \%)$ & 0.453 \\
\hline CHF, n (\%) & $36(33.3 \%)$ & $25(34.7 \%)$ & $24(40.7 \%)$ & 0.629 \\
\hline $\mathrm{CHD}, \mathrm{n}(\%)$ & $25(23.1 \%)$ & $23(31.9 \%)$ & $12(20.3 \%)$ & 0.258 \\
\hline Malignant tumor, $\mathrm{n}(\%)$ & $10(9.3 \%)$ & $9(12.5 \%)$ & $8(13.6 \%)$ & 0.654 \\
\hline ICU admission, n (\%) & $13(12.0 \%)$ & $5(6.9 \%)$ & $6(10.2 \%)$ & 0.539 \\
\hline WBC, I0^9/L (IQR) & $8.35(6.40,10.43)$ & $7.05(5.72,9.48)$ & $8.30(6.50,11.40)$ & 0.025 \\
\hline Neutrophils, I0^9/L (IQR), & $6.25(4.22,8.87)$ & $4.78(3.58,7.27)$ & $6.56(4.72,9.79)$ & 0.015 \\
\hline Lymphocytes, I0^9/L (IQR) & $1.20(0.78,1.73)$ & $1.30(0.79,1.68)$ & $1.02(0.82,1.37)$ & 0.123 \\
\hline NLR, (IQR) & $4.77(2.93,10.42)$ & $3.84(2.04,8.00)$ & $6.04(4.12,10.94)$ & 0.033 \\
\hline Hemoglobin, g/L (SD) & $130.76 \pm 18.39$ & $|26.0| \pm 26.25$ & $121.39 \pm 22.83$ & 0.031 \\
\hline PLT, I0^9/L (IQR) & $208.5(168.0,254.8)$ & $188.0(\mid 40.5,264.8)$ & $218.0(174.0,293.0)$ & 0.109 \\
\hline PLR, (IQR) & I73.8 (I I0.6, 258.3) & I67.I $(97.0,230.5)$ & $216.5(148.8,308.2)$ & 0.015 \\
\hline PDW, fL (IQR) & $12.6(11.3,14.2)$ & $12.7(11.3,14.6)$ & $12.9(10.7,14.2)$ & 0.718 \\
\hline C-reactive protein, mg/l (IQR) & $35.2(9.3,98.9)$ & $12.59(4.6,36.1)$ & $20.1(7.2,100.5)$ & 0.018 \\
\hline Procalcitonin $>0.05, \mathrm{n}(\%)$ & $54(50 \%)$ & 32 (44.4\%) & $32(54.2 \%)$ & 0.530 \\
\hline D-dimer, ug/mL (IQR) & $0.61(0.40,1.22)$ & $0.80(0.5 \mathrm{I}, \mathrm{I} .88)$ & $0.87(0.5 \mathrm{I}, \mathrm{I} .39)$ & 0.055 \\
\hline Creatinine, ummol/l (SD) & $69.30 \pm 40.47$ & $70.86 \pm 47.62$ & $62.47 \pm 27.60$ & 0.452 \\
\hline $\mathrm{pH}<7.35, \mathrm{n}(\%)$ & $25(23.1 \%)$ & $15(20.8 \%)$ & $13(22 \%)$ & 0.935 \\
\hline $\mathrm{PaCO} 2>45 \mathrm{mmHg}, \mathrm{n}(\%)$ & $60(55.6 \%)$ & $33(45.8 \%)$ & $34(57.6 \%)$ & 0.322 \\
\hline $\mathrm{PaO} 2<80 \mathrm{mmHg}, \mathrm{n}(\%)$ & 75 (69.4\%) & $42(58.3 \%)$ & 45 (76.3\%) & 0.082 \\
\hline Length of stay, days (IQR) & $10(8,14)$ & II $(8,15)$ & $10(8,13)$ & 0.673 \\
\hline 30-day readmission, n (\%) & $10(9.3 \%)$ & $7(9.7 \%)$ & $16(27.1 \%)$ & 0.003 \\
\hline $\begin{array}{l}\text { Number of admissions due to acute exacerbations during the } \\
\text { previous year, (IQR) }\end{array}$ & $0(0,1)$ & $I(0,1)$ & $0(0,1)$ & 0.070 \\
\hline
\end{tabular}

Abbreviations: COPD, chronic obstructive pulmonary disease; SO2, oxygen saturation; ICU, respiratory intensive care unit; CHF, chronic heart failure; CHD, coronary heart disease; WBC, white blood cell; NLR, neutrophil-lymphocyte ratio; PLT, platelets count; PLR, platelet-lymphocyte ratio; PDW, platelet distribution width; PO2, partial pressure of oxygen; PCO2, partial pressure of carbon dioxide.

conditions, such as iron, vitamin B12, and folic acid deficiency. ${ }^{22}$ Therefore, the presence of intense inflammation and oxidative stress may explain the correlation between high RDW values and disease prognosis.

Based on the current findings, the RDW is a marker of inflammation, disease severity, comorbidities, and prognosis in patients with COPD. Tertemiz et al showed that the RDW can be used as a marker of COPD severity. ${ }^{23}$ Subsequently, Kalemci confirmed the previously reported results. ${ }^{24}$ The RDW can also be used to predict high risk for COPD complicated with pulmonary hypertension, ${ }^{25}$ pulmonary embolism, ${ }^{26}$ and pulmonary heart disease. ${ }^{27}$ A study of 307 patients concluded that the RDW also has clinical diagnostic value for depression and/or anxiety associated with AECOPD, and may become a new indicator of inflammation in AECOPD. ${ }^{28} \mathrm{~A}$ retrospective study conducted by Epstein et al confirmed that an increased RDW is related to 60-day readmission of patients with AECOPD. Moreover, the study showed that chronic heart failure and discharge $\mathrm{pH}<7.35$ are also risk factors for the readmission of patients with COPD. ${ }^{29}$ $\mathrm{Hu}$ et al investigated the relationship between the RDW and acute exacerbations of COPD. They concluded that the RDW is a strong and independent risk factor for hospitalization and 1 -year death in patients with AECOPD. ${ }^{30}$ 
Table 2 Logistic Regression Analysis Between Demographic Factors, Vital Signs at Admission, Laboratory Test Results and 30-Day Readmission

\begin{tabular}{|c|c|c|c|c|}
\hline \multirow[t]{2}{*}{ Variable } & \multicolumn{2}{|c|}{ Univariate Analysis } & \multicolumn{2}{|c|}{ Multivariate Analysis } \\
\hline & OR $(95 \% \mathrm{Cl})$ & p-value & OR $(95 \% \mathrm{CI})$ & p-value \\
\hline Age & $1.01(0.97-1.04)$ & 0.744 & & \\
\hline Male gender & $0.89(0.34-2.32)$ & 0.811 & & \\
\hline Current smoker & $1.37(0.58-3.27)$ & 0.477 & & \\
\hline Charlson comorbidity index & $1.15(0.95-1.40)$ & 0.164 & $1.38(1.08-1.76)$ & 0.011 \\
\hline Heart rate at admission & $0.97(0.94-1.01)$ & 0.123 & & \\
\hline Respiratory rate at admission & $1.00(0.90-1.13)$ & 0.942 & & \\
\hline $\mathrm{SO} 2<90 \%$ at admission & $0.61(0.28-1.34)$ & 0.216 & & \\
\hline Systolic blood pressure $<100 \mathrm{mmHg}$ at admission & $1.04(0.29-3.76)$ & 0.947 & & \\
\hline Hypertension & $0.68(0.29-1.59)$ & 0.371 & & \\
\hline Diabetes & $0.96(0.3 \mathrm{I}-2.94)$ & 0.936 & & \\
\hline Chronic heart failure & $1.04(0.49-2.24)$ & 0.918 & & \\
\hline Coronary heart disease & $0.26(0.08-0.89)$ & 0.032 & $0.13(0.03-0.54)$ & 0.005 \\
\hline Malignant tumor & $2.50(0.97-6.50)$ & 0.059 & & \\
\hline Group: Normal group & - & - & - & - \\
\hline Decreased group & $1.06(0.38-2.91)$ & 0.917 & $1.12(0.39-3.20)$ & 0.828 \\
\hline Increased group & $3.65(1.53-8.68)$ & 0.003 & $3.45(1.39-8.58)$ & 0.008 \\
\hline Hemoglobin & $1.00(0.99-1.02)$ & 0.766 & & \\
\hline C-reactive protein & $1.00(0.99-1.00)$ & 0.373 & & \\
\hline Procalcitonin $>0.05$ & $0.72(0.34-1.52)$ & 0.391 & & \\
\hline $\mathrm{pH}<7.35$ at discharge & $2.30(1.05-5.05)$ & 0.038 & $2.43(1.04-5.69)$ & 0.041 \\
\hline $\mathrm{PaCO} 2>45 \mathrm{mmHg}$ at discharge & $1.42(0.67-3.01)$ & 0.356 & & \\
\hline $\mathrm{PaO} 2<80 \mathrm{mmHg}$ at discharge & $0.94(0.43-2.06)$ & 0.883 & & \\
\hline Length of stay & $0.97(0.90-1.04)$ & 0.368 & & \\
\hline Hospitalized due to AECOPD during the previous year & $1.43(0.68-3.03)$ & 0.347 & & \\
\hline
\end{tabular}

Abbreviations: OR, odds ratios; $95 \% \mathrm{Cl}, 95 \%$ confidence intervals; RDW, red cell distribution width; SO2, oxygen saturation; PO2, partial pressure of oxygen; PCO2, partial pressure of carbon dioxide.

An increased RDW is closely associated with the severity of COPD. In addition, it acts as a sign of pulmonary hypertension and right heart dysfunction, which can assist in the prompt identification of COPD patients with acute heart failure. ${ }^{25,31,32}$ In short, a high RDW value is the result of a combination of multiple factors. The correlation between the RDW and inflammation, oxidative stress, tissue hypoxia, disease severity, and heart failure may help researchers understand the relationship of this marker with poor outcomes in patients with AECOPD.

The RDW increases in response to the destruction of red blood cells or impairment of their production. ${ }^{18}$ Certain pathological conditions in the organism may promote the occurrence and development process of RDW increasing. ${ }^{10}$ The duration of an elevation in the RDW depends on the duration of the stimulus (disease episode) and the subsequent persistence of the RDW signal. ${ }^{10}$ Severe and complex disease conditions can also prolong the duration of RDW elevation. ${ }^{10}$ Therefore, we suggest that the dynamic increase of the RDW could accurately reflect the changes in underlying disease. Earlier studies of acute heart failure performed by Makhoul et al confirmed that dynamic measurements of the RDW have stronger prognostic capacity than single measurements. ${ }^{11}$ Furthermore, Uemura et al demonstrated that change in the RDW independently predicts adverse outcomes in patients with acute decompensated heart failure. ${ }^{14}$ Regarding chronic heart failure, a retrospective study of 6159 patients indicated that a progressive increased in the RDW is related to poor outcomes in such patients. ${ }^{9}$ Kim also suggested that a dynamic increase in the RDW is a promising independent prognostic indicator in patients with severe sepsis or septic shock. ${ }^{13}$ Similarly, Ju et al showed that a dynamic increase in the RDW was more useful in predicting prognosis among elderly patients with septic shock. ${ }^{33}$ Yoon et al proved that a dynamic increase in the RDW predicts the occurrence of adverse events in patients with end-stage renal disease. ${ }^{15}$ The study conducted by Yazıc1 on pulmonary embolism also confirmed the 


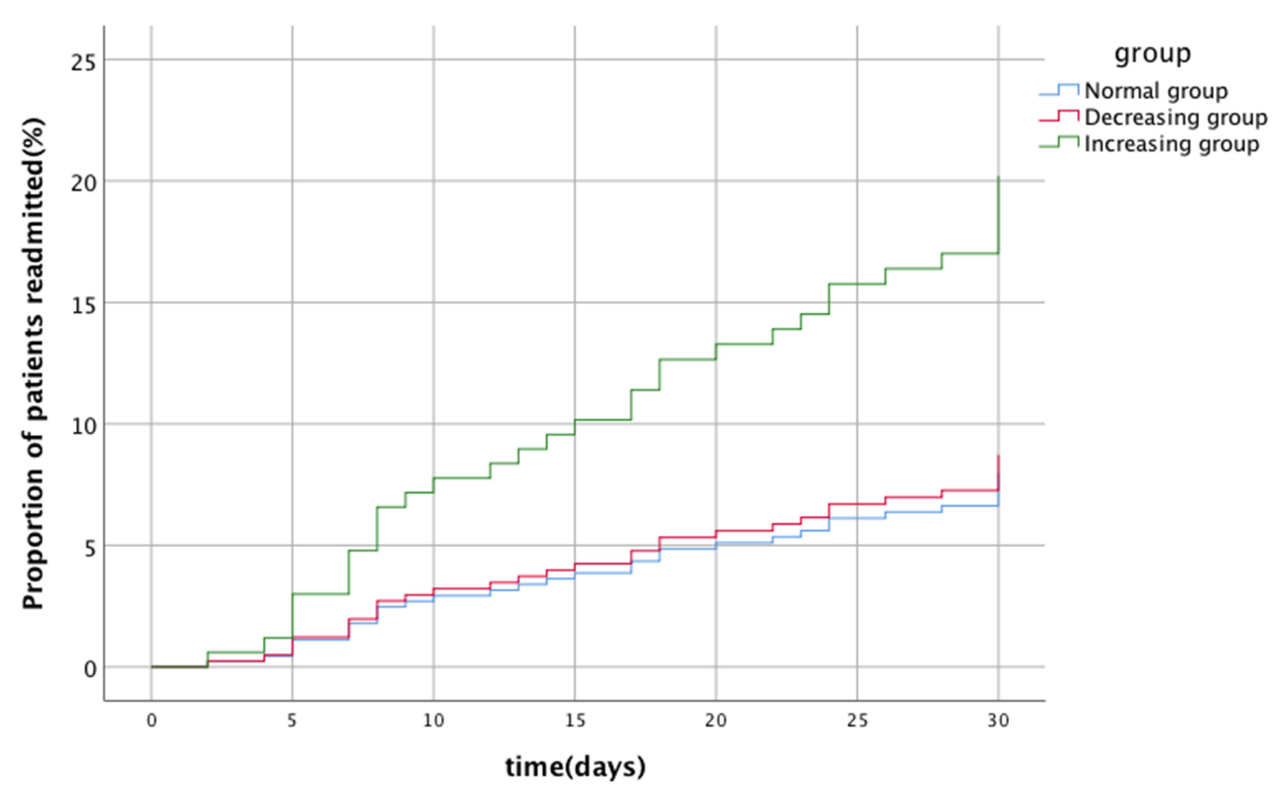

Figure 2 Adjusted survival curve for 30-day all-cause readmission according to RDW group ( $p=0.015)$.

importance of the dynamic measurement of the RDW. ${ }^{12}$ Considering the aforementioned previous studies, the present findings suggest that a dynamic increase in the RDW may be more valuable in the prognosis of patients with AECOPD.

\section{Research Limitations}

There were some limitations in this study. Firstly, this was a single-center retrospective study with a limited sample, no formal sample size calculations were performed. Secondly, the RDW is affected by a number of factors that were not assessed in this investigation, including iron, folic, and vitamin B12. Thirdly, we did not discriminate respiratory system readmission from all-cause readmission. Fourthly, we were unable to include some patients in the study analysis due to their lung function results at different hospitalization periods. Nevertheless, all included patients underwent at least one lung function test to support the diagnosis. Finally, it is uncertain whether changes in the RDW occurring within 4 days can accurately represent pathophysiological changes of the disease. However, the measurement time and grouping of the RDW were conducted strictly in accordance with the protocols of previous studies.

\section{Conclusions}

A dynamic increase in RDW is an independent prognostic factor related to 30-day all-cause readmission of patients with AECOPD. Continuous measurement of the RDW can help physicians in identifying patients at high risk of shortterm adverse outcomes. This cost-effective and common laboratory parameter provides useful prognostic information and may improve decisions regarding discharge from hospital. Patients with a dynamic increase in RDW should be managed more carefully and closely to improve their clinical prognosis. Furthermore, use of the RDW can reduce the medical cost associated with repeated hospitalization and reduce the waste of medical resources.

\section{Abbreviations}

RDW, red cell distribution width; COPD, chronic obstructive pulmonary disease; AECOPD, acute exacerbation of chronic obstructive pulmonary disease; OR, odds ratios; 95\% CI, 95\% confidence intervals.

\section{Data Sharing Statement}

Data for this study are available from the corresponding author.

\section{Acknowledgments}

Thanks to Yulan Zeng MD for her suggestions on the revision of the article and her help with the language editing.

\section{Funding}

The authors received no financial support for the research, authorship, and/or publication of this article. 


\section{Disclosure}

The authors report no conflicts of interest.

\section{References}

1. Decramer M, Janssens W, Miravitlles M. Chronic obstructive pulmonary disease. Lancet. 2012;379(9823):1341-1351. doi:10.1016/ S0140-6736(11)60968-9

2. Celli BR, Wedzicha JA. Update on clinical aspects of chronic obstructive pulmonary disease. $N$ Engl $J$ Med. 2019;381 (13):1257-1266. doi:10.1056/NEJMra1900500

3. Bagdonas E, Raudoniute J, Bruzauskaite I, Aldonyte R. Novel aspects of pathogenesis and regeneration mechanisms in COPD Int J Chron Obstruct Pulmon Dis. 2015;10. doi:10.2147/COPD. S 82518

4. Shah T, Press VG, Huisingh-Scheetz M, White SR. COPD readmissions: addressing COPD in the era of value-based health care. Chest 2016;150(4):916-926. doi:10.1016/j.chest.2016.05.002

5. Gershon AS, Thiruchelvam D, Aaron S, et al. Socioeconomic status (SES) and 30-day hospital readmissions for chronic obstructive pulmonary (COPD) disease: a population-based cohort study. PLoS One. 2019;14(5):e0216741. doi:10.1371/journal.pone.0216741

6. de Miguel-díez J, Jiménez-García R, Hernández-Barrera V, et al. Readmissions following an initial hospitalization by COPD exacerbation in Spain from 2006 to 2012. Respirology. 2016;21(3):489-496. doi:10.1111/resp. 12705

7. Goto T, Faridi MK, Gibo K, et al. Trends in 30-day readmission rates after COPD hospitalization, 2006-2012. Respir Med. 2017;130:92-97. doi:10.1016/j.rmed.2017.07.058

8. Salvagno GL, Sanchis-Gomar F, Picanza A, Lippi G. Red blood cell distribution width: a simple parameter with multiple clinical applications. Crit Rev Clin Lab Sci. 2020;15(2):2. doi:10.3109/ 10408363.2014.992064

9. Cauthen CA, Tong W, Jain A, Tang WHW. Progressive rise in red cell distribution width is associated with disease progression in ambulatory patients with chronic heart failure. J Card Fail. 2012;18 (2):146-152. doi:10.1016/j.cardfail.2011.10.013

10. Yčas JW, Horrow JC, Horne BD. Persistent increase in red cell size distribution width after acute diseases: a biomarker of hypoxemia? Clin Chim Acta. 2015;448:107-117. doi:10.1016/j.cca.2015.05.021

11. Makhoul BF, Khourieh A, Kaplan M, Bahouth F, Aronson D, Azzam ZS. Relation between changes in red cell distribution width and clinical outcomes in acute decompensated heart failure. Int $J \quad$ Cardiol. 2013;167(4):1412-1416. doi:10.1016/j. ijcard.2012.04.065

12. Yazııı S, Kırış T, Sadık Ceylan U, et al. Relation between dynamic change of red cell distribution width and 30-day mortality in patients with acute pulmonary embolism. Clin Respir J. 2018;12(3):953-960. doi:10.1111/crj.12611

13. Kim CH, Park JT, Kim EJ, et al. An increase in red blood cell distribution width from baseline predicts mortality in patients with severe sepsis or septic shock. Crit Care. 2013;17(6):R282. doi:10.1186/cc13145

14. Uemura Y, Shibata R, Takemoto K, et al. Elevation of red blood cell distribution width during hospitalization predicts mortality in patients with acute decompensated heart failure. $J$ Cardiol. 2016;67 (3):268-273. doi:10.1016/j.jjcc.2015.05.011

15. Yoon HE, Kim SJ, Hwang HS, Chung S, Yang CW, Shin SJ. Progressive rise in red blood cell distribution width predicts mortality and cardiovascular events in end-stage renal disease patients. PLoS One. 2015;10(5):e0126272. doi:10.1371/journal.pone.0126272

16. Vogelmeier CF, Román-Rodríguez M, Singh D, Han MK, RodríguezRoisin R, Ferguson GT. Goals of COPD treatment: focus on symptoms and exacerbations. Respir Med. 2020;166:105938. doi:10.1016/ j.rmed.2020.105938
17. Karampitsakos T, Dimakou K, Papaioannou O, et al. The role of increased red cell distribution width as a negative prognostic marker in patients with COPD. Pulm Pharmacol Ther. 2020;60:101877. doi:10.1016/j.pupt.2019.101877

18. Yčas JW. Toward a blood-borne biomarker of chronic hypoxemia: red cell distribution width and respiratory disease. Adv Clin Chem. 2017;82:105-197.

19. Patel KV, Mohanty JG, Kanapuru B, Hesdorffer C, Ershler WB, Rifkind JM. Association of the red cell distribution width with red blood cell deformability. Adv Exp Med Biol. 2013;765:211-216.

20. Pierce CN, Larson DF. Inflammatory cytokine inhibition of erythropoiesis in patients implanted with a mechanical circulatory assist device. Perfusion. 2005;20(2):83-90. doi:10.1191/ 0267659105pf793oa

21. Ghaffari S. Oxidative stress in the regulation of normal and neoplastic hematopoiesis. Antioxid Redox Signal. 2008;10(11):1923-1940. doi: $10.1089 /$ ars. 2008.2142

22. Jelkmann W. Proinflammatory cytokines lowering erythropoietin production. $J$ Interferon Cytokine Res. 1998;18(8):555-559. doi:10.1089/jir.1998.18.555

23. Tertemiz KC, Ozgen Alpaydin A, Sevinc C, Ellidokuz H, Acara AC, Cimrin A. Could "red cell distribution width" predict COPD severity? Rev Port Pneumol. 2016;22(4):196-201. doi:10.1016/j. rppnen.2015.11.006

24. Kalemci S, Akin F, Sarihan A, Sahin C, Zeybek A, Yilmaz N. The relationship between hematological parameters and the severity level of chronic obstructive lung disease. Pol Arch Intern Med. 2018;128 (3):171-177. doi:10.20452/pamw.4198

25. Yang J, Liu C, Li L, Tu X, Lu Z. Red blood cell distribution width predicts pulmonary hypertension secondary to chronic obstructive pulmonary disease. Can Respir J. 2019;2019:3853454. doi:10.1155/ 2019/3853454

26. Wang J, Wan Z, Liu Q, et al. Predictive value of red blood cell distribution width in chronic obstructive pulmonary disease patients with pulmonary embolism. Anal Cell Pathol. 2020;2020:1935742.

27. Bai Y, Tao X-N. Mean platelet volume combined red cell distribution width as biomarker of chronic obstructive pulmonary disease with pulmonary heart disease. Clin Respir J. 2020;14(12):1122-1130. doi:10.1111/crj.13248

28. Long J, Ouyang Y, Duan H, et al. Multiple factor analysis of depression and/or anxiety in patients with acute exacerbation chronic obstructive pulmonary disease. Int J Chron Obstruct Pulmon Dis. 2020;15:1449-1464. doi:10.2147/COPD.S245842

29. Epstein D, Nasser R, Mashiach T, Azzam ZS, Berger G. Increased red cell distribution width: a novel predictor of adverse outcome in patients hospitalized due to acute exacerbation of chronic obstructive pulmonary disease. Respir Med. 2018;136:1-7. doi:10.1016/j. rmed.2018.01.011

30. Hu GP, Zhou YM, Wu ZL, et al. Red blood cell distribution width is an independent predictor of mortality for an acute exacerbation of COPD. Int J Tuberc Lung Dis. 2019;23(7):817-823. doi:10.5588/ ijtld.18.0429

31. Sincer I, Zorlu A, Yilmaz MB, et al. Relationship between red cell distribution width and right ventricular dysfunction in patients with chronic obstructive pulmonary disease. Heart Lung. 2012;41 (3):238-243. doi:10.1016/j.hrtlng.2011.07.011

32. Ozgul G, Seyhan EC, Özgül MA, Günlüoğlu MZ. Red blood cell distribution width in patients with chronic obstructive pulmonary disease and healthy subjects. Arch Bronconeumol. 2017;53 (3):107-113. doi:10.1016/j.arbres.2016.05.021

33. Ju X-F, Wang F, Wang L, et al. Dynamic change of red cell distribution width levels in prediction of hospital mortality in Chinese elderly patients with septic shock. Chin Med J. 2017;130(10):1189-1195. doi:10.4103/0366-6999.205858 


\section{Publish your work in this journal}

The International Journal of COPD is an international, peer-reviewed journal of therapeutics and pharmacology focusing on concise rapid reporting of clinical studies and reviews in COPD. Special focus is given to the pathophysiological processes underlying the disease, intervention programs, patient focused education, and self management protocols. This journal is indexed on PubMed Central, MedLine and CAS. The manuscript management system is completely online and includes a very quick and fair peer-review system, which is all easy to use. Visit http://www.dovepress.com/testimonials.php to read real quotes from published authors. 